\title{
Como as Entrevistas com Engenheiros Eletrônicos da Petrobras nos Ajudam a Pensar Matemática nos Cursos de Serviço
}

\author{
How Interviews with Petrobras Electronic Engineers Help us to Think \\ About Mathematics in Service Courses
}

\author{
Rejane Siqueira Julio* \\ ORCID iD 0000-0002-3248-800X \\ Alexandrina Monteiro** \\ ORCID iD 0000-0002-5803-1358
}

\begin{abstract}
Resumo
Neste artigo, propomos duas discussões sobre a Matemática em cursos de serviço, uma relacionada a práticas problematizadoras, que amplia a perspectiva da resolução de problemas no aspecto de não somente resolver problemas dados, como também de inventar novos problemas ou novas formas de vida que requerem novas técnicas, e outra sobre a atuação docente focada em formas de ação, e não apenas em conteúdos. Isso é feito por meio de recortes de entrevistas realizadas com engenheiros eletrônicos atuantes em diferentes áreas de negócio da Petrobras. Por meio delas são exibidos diferentes modos de ver a Matemática no mundo profissional e as relações que são estabelecidas entre a Matemática no trabalho e na formação universitária.
\end{abstract}

Palavras-chave: Modos de Ver a Matemática. Problematização. Prática Docente. Educação em Engenharia. Educação Matemática.

\begin{abstract}
In this paper, we propose two discussions about mathematics in service courses, one related to problematizing practices that enlarge the perspective of problem-solving not only about solving given problems, but also of inventing new techniques and new forms of life, and another about the teaching activity focused on forms of action and not only on content. We did all discussions through excerpt of interviews made with electronic engineers working in different Petrobras' business areas. Through them, we exhibited different ways of viewing mathematics in the professional world and the relationships between mathematics at work and in university education.
\end{abstract}

Keywords: Ways of Viewing Mathematics. Problematizing. Teaching Activity. Engineering Education. Mathematics Education.

\footnotetext{
* Doutora em Educação pela Unicamp. Docente do Departamento de Matemática do Instituto de Ciências Exatas e do Programa de Pós-Graduação em Educação da Universidade Federal de Alfenas (UNIFAL-MG), Alfenas, Minhas Gerais, Brasil. Endereço para correspondência: Rua Gabriel Monteiro da Silva, 700, Centro, Alfenas, Minhas Gerais, Brasil, CEP: 37139-001. E-mail: rejane.julio@unifal-mg.edu.br ou resiju@gmail.com.

** Doutora em Educação pela Unicamp. Docente da Faculdade de Educação da Unicamp, Campinas, São Paulo, Brasil. Endereço parra correspondência: Rua Antônio Falcaro, 64, Sousas, Campinas, São Paulo, Brasil, CEP: 13.105-662. E-mail: E-mail: alemath@unicamp.br.
} 


\title{
1 Introdução
}

Os saberes que compõem o campo que denominamos por Matemática Acadêmica estão presentes em muitos cursos superiores na forma de disciplinas. Em alguns deles, como é o caso dos cursos de engenharia, essas disciplinas são entendidas como fundamentos inquestionáveis para a formação profissional, como é o caso do Cálculo Diferencial e Integral e da Geometria Analítica - entre outras. Essa inequivocidade é justificada, por alguns engenheiros com a afirmação de que: "tudo na vida do engenheiro tem matemática"1.

Telles (1984) apresenta um histórico sobre a Engenharia no Brasil, no qual mostra a importância do papel atribuído à Matemática não apenas para a formação e a prática do engenheiro, mas também para o próprio desenvolvimento da Engenharia:

\begin{abstract}
pode-se dizer que a engenharia científica [ou moderna] só teve início quando se começou a chegar a um consenso de que tudo aquilo que se fazia em bases empíricas e intuitivas, era na realidade regida por leis físicas e matemáticas, que importava descobrir e estudar. Leonardo da Vinci e Galileu, nos sécs. XV e XVII, podem ser considerados como os precursores da engenharia científica. [...] daí por diante, aos poucos, a engenharia foi se estruturando, à medida também que se desenvolviam as ciências matemáticas, mas somente no séc. XVIII foi possível chegar-se a um conjunto sistemático e ordenado de doutrinas, que constituíram a primeira base teórica da engenharia (TELLES, 1984, p. 2).
\end{abstract}

Ainda nesse sentido, Bazzo e Pereira (2006) também abordam a relação da Matemática com o desenvolvimento da Engenharia, afirmando que o aparecimento formal do engenheiro resultou de um longo processo de desenvolvimento de atividades que foram se estruturando, sendo "fruto fundamentalmente do desenvolvimento da matemática, da explicação dos fenômenos físicos, dos experimentos realizados - em ambiente controlado -, da prática de campo, da sistematização de cursos formais" (BAZZO; PEREIRA, 2006, p. 69).

Diante disso, podemos afirmar que a Matemática vem assumindo um importante papel na profissionalização da Engenharia no Brasil desde os primeiros currículos elaborados. Vale aqui ressaltar que esses currículos tiveram forte influência do sistema francês, tanto no que se refere às disciplinas técnicas, quanto às disciplinas vinculadas aos campos denominados básicos, como Matemática, Física e Química. Mesmo sofrendo diversas reformulações curriculares exemplificadas por Telles (1984), as disciplinas de Cálculo Diferencial e Integral e Geometria Analítica - inserida no currículo posteriormente, sob influência positivista (SILVA, 1999) -, permaneceram inalteradas em suas estruturas.

\footnotetext{
${ }^{1}$ Esta justificativa esteve presente na maioria das falas dos engenheiros entrevistados na pesquisa desenvolvida por uma das autoras deste artigo. Tal pesquisa será apresentada adiante.
} 
A manutenção das disciplinas de Matemática na formação do engenheiro é vista nas Diretrizes Curriculares Nacionais do Curso de Graduação em Engenharia ${ }^{2}$ (BRASIL, 2002), que definem como devem ser organizados os currículos dos cursos de engenharia, ou seja, apresentam "os princípios, fundamentos, condições e procedimentos da formação de engenheiros [...], para aplicação em âmbito nacional na organização, desenvolvimento e avaliação dos projetos pedagógicos dos Cursos de Graduação em Engenharia [...]" (BRASIL, 2002, p. 1).

Seguindo uma lógica estruturalista, esse documento lista, logo no início, as competências e as habilidades que devem ser desenvolvidas durante a formação do engenheiro, dentre elas: "aplicar conhecimentos matemáticos, científicos, tecnológicos e instrumentais à engenharia" (BRASIL, 2002, p. 1). Após esse início, o destaque à Matemática é dado no quinto tópico da listagem do núcleo de conteúdos básicos (do $§ 1$ do $\operatorname{Art} .6^{\circ}$ ), que corresponde a, aproximadamente, $30 \%$ da carga horária mínima dos cursos de Engenharia (BRASIL, 2002). Ademais, aparece novamente no $\S 3$ do Art. $6^{\circ}$ das Diretrizes, que versa sobre um subconjunto dos tópicos do núcleo de conteúdos profissionalizantes, correspondente a cerca de $15 \%$ da carga horária mínima dos cursos, dentre eles: Matemática Discreta, Métodos Numéricos e Pesquisa Operacional. ${ }^{3}$

Essa presença explícita e valorizada de campos de saberes matemáticos nos documentos oficiais brasileiros - que balizam a elaboração de projetos pedagógicos de muitos cursos universitários, dentre eles os da Engenharia -, reforça o lugar inequívoco que eles ocupam.

Para lidar com esses saberes na formação universitária, Barbosa (2004) comenta que, no campo da Educação Matemática, eles têm sido debatidos a partir de diferentes perspectivas, sendo a primeira sobre os conteúdos matemáticos que devem integrar o programa das disciplinas de Matemática, a segunda sobre a maneira de estruturar as disciplinas (seja por meio de apoios aos alunos, como atendimentos extraclasse e monitorias, ou de propostas baseadas no trabalho do aluno) e, por fim, a terceira, relacionada às condições oferecidas aos alunos para desenvolverem atividades específicas dentro do contexto geral da

\footnotetext{
${ }^{2}$ Doravante Diretrizes.

${ }^{3}$ Aqui surge um problema relativo àquilo que podemos considerar como "Matemática". Até que ponto tópicos como Algoritmos e Estruturas de Dados ou Modelagem, Análise e Simulação de Sistemas, por exemplo, podem ou não serem considerados "Matemática"? Não é nosso objetivo discutir isso aqui e, sim, exemplificar que a Matemática, de acordo com as Diretrizes, participa tanto do núcleo de conteúdos básicos quanto do núcleo de conteúdos profissionalizantes.
} 
disciplina, como, por exemplo, a utilização de tecnologias informáticas e aplicações da Matemática.

Neste artigo, queremos apontar outro aspecto relacionado ao debate sobre a presença da Matemática em cursos de graduação, mas que, de certa forma, acaba perpassando essas perspectivas apontadas por Barbosa (2004). Trata-se de olhar para a Matemática do ponto de vista da prática profissional e a relação que pode ser estabelecida entre ela e as práticas de formação matemática nos cursos universitários, com o objetivo de contribuir para a construção de outras possibilidades de docência nesses cursos, como as práticas problematizadoras e docência focada em formas de ação, não apenas em conteúdos.

Esse modo de olhar pauta-se nos escritos do segundo Wittgenstein ${ }^{4}$ (2009) sobre a Matemática, nos quais ele afirma: “[é] evidente que a matemática, em certo sentido, é uma doutrina [...] [, mas ela] é, também, um fazer" (WITTGENSTEIN, 2009, p. 292). Podemos assim pensar a Matemática como uma prática problematizável, uma ação humana situada no tempo e no espaço, o que a coloca em movimento no mundo, ainda que possa parecer estável e estática nos currículos escolares.

Wittgenstein (2009) afirma, ainda, que jogos de linguagem podem ser vistos como "a totalidade formada pela linguagem e pelas atividades com as quais ela vem entrelaçada" (WITTGENSTEIN, 2009, p. 7). Desse modo, são exemplos de jogos de linguagem: ordenar e agir segundo ordens; descrever um objeto pela aparência ou por suas medidas; relatar um acontecimento; levantar uma hipótese e examiná-la; apresentar os resultados de um experimento por meio de tabelas e diagramas; inventar uma história; pedir; agradecer; praguejar; cumprimentar; assim como rezar (WITTGENSTEIN, 2009, p. 23). Ao afirmar que os exemplos de práticas que realizamos em nosso dia a dia são vistos como jogos de linguagem, Wittgenstein (2009) nos permite também afirmar que há uma conexão entre jogos de linguagem e práticas, sejam elas profissionais, formativas, dentre outras.

Nesse sentido, "[a]o mesmo tempo em que as práticas são vistas como jogos de linguagem, estes, por sua vez, são vistos como práticas. E é nesse sentido que os jogos de linguagem são, ao mesmo tempo, constitutivos das práticas e constituídos nas e pelas práticas" (MIGUEL, 2010, p. 45). Diante disso, e compreendendo a Matemática ou os saberes como um fazer humano situado no tempo e no espaço, podemos ver a Matemática ou os

\footnotetext{
4 "Segundo Wittgenstein" é uma classificação feita para caracterizar os pensamentos do filósofo austríaco Ludwig Wittgenstein após o Tractatus Logico-Philosophicos (WITTGENSTEIN, 2010) e presentes nas Investigações Filosóficas (WITTGENSTEIN, 2009) e em escritos da época dessa obra.
} 
saberes como jogos de linguagem e, desse modo, compreendê-los de forma mais ampla. Mas o que isso significa?

Em vez de buscar uma essência que represente a pedra fundamental da Matemática ou dos saberes, por exemplo, no sentido de dizer o que eles são, passamos a vê-los como uma família de atividades com uma família de propósitos (WITTGENSTEIN, 1980) que podem ser realizados "pelos matemáticos profissionais, pelos professores de matemática, pelas diferentes comunidades constituídas com base em vínculos profissionais, bem como pelas pessoas em geral em suas atividades cotidianas" (MIGUEL; VILELA, 2008, p. 112).

Assim, tanto a nossa leitura de Wittgenstein $(2009 ; 1980)$ quanto os estudos sobre as práticas profissionais em seus campos de trabalho, nos possibilitam pensar a Matemática e os saberes de outras formas,

o que emerge claramente [nestes estudos] é que as pessoas desenvolvem estratégias para realizar seus trabalhos rapidamente e eficientemente usando seus conhecimentos e experiências, mas, também, explorando características dos seus meios e suas regularidades locais. Isto é, nesse sentido, que o conhecimento forma e é formado pelas atividades do local de trabalho (NOSS; HOYLES; POZZI, 2002, p. 17).

O entendimento de que os saberes das práticas profissionais são, também, construções elaboradas no ambiente de trabalho minimiza e fragiliza a crença de que as universidades fornecem, ao longo dos anos de formação, um conjunto de conhecimentos, dentre eles, os conhecimentos matemáticos, que depois serão aplicados no mundo profissional, como se fossem uma via de mão única e de transmissão direta de conhecimentos.

Desse modo, nos parece fundamental reconhecer a necessidade de serem feitas pesquisas sobre como são mobilizados os saberes, dentre eles os saberes matemáticos no exercício das práticas profissionais, especialmente no caso de profissões vinculadas a atividades não acadêmicas. No entanto, "nossa indústria, nossa técnica, nossa ciência, nossa administração, permanecem bem pouco estudadas" (LATOUR; WOOLGAR, 1997, p. 18) e essa constatação de Latour e Woolgar (1997) pode ser confirmada na ausência de dissertações e teses de mestrado e doutorado defendidas no Brasil e inseridas no Banco de Teses da CAPES $^{5}$ ou nas edições da Revista de Educação Matemática Zetetiké, ${ }^{6}$ envolvendo saberes matemáticos mobilizados pelas práticas que se operam no desenvolvimento das atividades,

\footnotetext{
${ }^{5}$ Disponível em: <http://bancodeteses.capes.gov.br/>. Acesso em: 15 jul. 2013.

${ }^{6}$ A Revista Zetetiké apresenta uma listagem de teses e dissertações em Educação Matemática defendidas no Brasil desde 1991 e suas edições podem ser acessadas na página: http://www.fae.unicamp.br/revista/index.php/ zetetike/issue/archive. Acesso em: 15 jul. 2013.
} 
por exemplo, exercidas por uma equipe de trabalho de engenharia no interior de uma indústria.

Dessa forma, este artigo pretende contribuir com elementos que nos permitam produzir outros sentidos, outros modos de pensar a Matemática e seu ensino. Para tanto, vamos nos apoiar em entrevistas realizadas com engenheiros eletrônicos da Petrobras, ${ }^{7}$ alocados em suas diferentes áreas de negócio. O objetivo dessas entrevistas foi compreender as relações que esses profissionais estabelecem entre os usos da Matemática em suas práticas profissionais e a sua formação matemática escolar, em especial a universitária. No texto aqui apresentado selecionamos recortes dessas entrevistas realizadas por Julio (2015).

As entrevistas com esse grupo de engenheiros foram organizadas a partir de um roteiro que possibilitasse ao profissional comentar sobre sua formação universitária, sua formação na Universidade Petrobras, ${ }^{8}$ os saberes matemáticos que mobiliza em sua atuação profissional, assim como quais relações estabelecem ou não entre esses saberes e aqueles que foram trabalhados no contexto de escolarização - em qualquer nível. Além disso, propusemos a todos uma questão: o que é tão inequívoco como $2+2=4$ nas atividades que exerce?

Esse roteiro foi desenvolvido com inspiração nos escritos de Wittgenstein (1978; 2009), em particular nos que mencionam jogos de linguagem, regras e semelhanças de família e a importância das descrições e exemplificações, como descrito em detalhes em Julio (2016). Estas palavras e expressões nos guiaram no aspecto metodológico das análises que fizemos das entrevistas e dos trechos aqui trazidos para as discussões nos quais dialogamos, também, com as teorizações realizadas por Miguel (2010) e Miguel e Vilela (2008), que veem práticas como jogos de linguagem e por Gebauer (2013), sobre a diferença de jogos de linguagem da ação e do falar sobre a ação.

\section{A Matemática no mundo profissional}

Antes de entrarmos nos recortes das entrevistas em que alguns engenheiros eletrônicos falaram sobre a Matemática em suas práticas profissionais, é importante traçar uma distinção entre dois jogos de linguagem, ou seja, o de falar sobre a própria prática e do agir efetivamente na prática, conforme aponta Gebauer (2013):

\footnotetext{
${ }^{7}$ Fundada em 1953, a Petrobras é uma sociedade anônima de capital aberto que tem como acionista majoritário o governo brasileiro. Ela é uma empresa líder no setor petrolífero brasileiro, estando presente, também, em outros países. Disponível em: <http://www.petrobras.com.br/pt/quem-somos/perfil/>. Acesso em: 24 abr. 2015.

${ }^{8}$ A Universidade Petrobras se caracteriza como um espaço educacional coorporativo de formação e educação continuada inserido nas estratégias de negócios da Petrobras.
} 
a capacidade de ação por parte do falante experiente mostra-se no próprio agir. No entanto, quando exigimos dele que justifique explicitamente suas ações, estamos exigindo dele um jogo de linguagem especial, que não faz parte do seguimento da regra da ação. Em muitos casos, que vemos muito naturalmente como atos do seguimento de regra, essa exigência não pode ser cumprida pelo agente; por exemplo, um falante não pode, em muitos casos, indicar as regras segundo as quais as frases são formadas em sua língua materna. As reflexões sobre regras da ação e sua justificação pressupõem um jogo de linguagem especial e conhecimentos explícitos, que são diferentes daqueles da compreensão prática e devem ser adquiridos em contextos específicos, por exemplo, gramaticais, éticos, jurídicos, científicos e pedagógicos. Eles pertencem ao âmbito do pensamento escolástico, que é separado da práxis por um corte epistemológico (GEBAUER, 2013, p. 130).

É importante marcar esta diferença de jogos de linguagem, como faz Gebauer (2013), porque no processo de entrevistas, há um deslocamento entre o fazer de uma pessoa no contexto do dia a dia de trabalho para o contexto de descrição e explicação de sua prática profissional. Um processo que, por se tratar de uma empresa de grande porte, envolve, também, silêncios, sigilos de informação e um cuidado sobre o que falar. Ainda que isso ocorra, esses jogos de linguagem não são incomunicáveis, eles “estão aí mais como objetos de comparação, os quais, por semelhança e dissemelhança, devem lançar luz nas relações de nossa linguagem" (WITTGENSTEIN, 2009, p. 130). Essas semelhanças e dissemelhanças são o que Wittgenstein chamou de semelhanças de família:

não posso caracterizar melhor essas semelhanças do que por meio das palavras "semelhanças familiares"; pois assim se sobrepõem e se entrecruzam as várias semelhanças que existem entre os membros de uma família: estatura, traços fisionômicos, cor dos olhos, andar, temperamento, etc., etc. - E eu direi: os "jogos" formam uma família. Do mesmo modo formam uma família, p. ex., as espécies de números. Por que chamamos algo de "número"? Ora, talvez porque tem um-diretoparentesco com alguma coisa que até agora se chamou de número; e pode-se dizer que através disso adquire um parentesco com uma outra coisa que também chamamos assim. E alargamos nosso conceito de número do mesmo modo que, ao tecermos um fio, traçamos fibra por fibra. E a robustez do fio não consiste em que uma fibra qualquer perpasse toda sua extensão, mas em que muitas fibras se sobreponham umas às outras (WITTGENSTEIN, 2009, p. 67).

Para Wittgenstein (2009) não há algo que seja comum ou essencial a todos os jogos de linguagem e sim semelhanças de famílias que podem ser lidas neles e que nos permitem aproximá-los ou distanciá-los. Para realizar esta leitura se torna importante explorar, ao máximo, descrições e exemplificações desses jogos em momentos de entrevistas ou pesquisas que tenham como foco as práticas que são executadas pelas pessoas. Isso foi algo que priorizamos nas entrevistas e consideramos nas escolhas dos recortes que selecionamos para serem analisados. No nosso caso, as considerações e os recortes que aqui serão discutidos também são fruto de uma análise que considerou algumas observações da atuação dos entrevistados. 
Essa aproximação duplicada junto ao sujeito entrevistado é decorrente da crença de que os jogos de linguagem presentes nas narrativas sobre as práticas e os jogos que operam as ações, o agir no trabalho, podem apresentar semelhanças de família entre si. Desse modo, entendemos que focar essas semelhanças poderia intensificar a possibilidade de análise de como a Matemática é vista por engenheiros da Petrobras em suas práticas. Nos recortes das entrevistas que se seguem, os engenheiros serão identificados por Siglas E1, E2, ou seja, E seguido de um algarismo.

Um dos entrevistados que trouxemos para este artigo foi o engenheiro E2, alocado na Universidade Petrobras. Ele trabalha como docente em cursos de formação de engenheiros mantidos pela Petrobras e atua também em pesquisas e projetos que envolvem, dentre outras coisas, controle de processos, automação industrial e otimização em tempo real. Sobre a matemática nos cursos de formação, E2 fala que:

no curso de Engenharia Eletrônica [Curso de Formação em Automação Industrial], as disciplinas que eu dei não envolvem tanto a matemática, porque são descrições um pouco mais qualitativas. Só que, como eu sei que o pessoal tem um background, muitas vezes eu puxo a discussão para isso, porque o pessoal está muito familiarizado com os conceitos de controle de processos e, em controle de processos, a base para o cara entender tem que passar pela matemática. Então, [nessa disciplina] de processos de refino, ela não é explícita. Na ementa da disciplina não contém isso. Contém nas disciplinas de controle de processos, [...] para a formação de engenheiros de Processamento [para engenheiros que tem formação em Engenharia Química], aí se baseia em resolver sistema de equações diferenciais, colocar o problema de controle lá dento, ver as questões de estabilidade, [...] matemática de forma explícita, transformadas de Laplace.

(Entrevista com E2, 2015).

Para o desenvolvimento de seus cursos, E2 trabalha com uma série de softwares que desenvolveu e exemplifica um deles, que trata de um controle interativo para o controle de uma variável do processo de refino, como vemos a seguir.

Muitas vezes você tem um sistema que é um controle automático e você coloca ele na planta
para tentar fazer uma variável do seu processo ficar constante [como é o caso de uma
temperatura]. Se [o controlador] perceber que a temperatura se desviou, ele vai em alguma
válvula, mexe nessa válvula continuamente até conseguir fazer com que a temperatura volte.
E aqui [nesse software] a gente vê alguns aspectos de como é que você parametriza esses
controladores e, também, acaba tendo uma espécie de um jogo, onde o aluno se coloca na
posição do controlador. Ao invés do controlador ser automático, ele passa a ser manual, [o
aluno] passa a ter acesso a essa válvula onde ele vai mexer e o processo vai recebendo
perturbaçóes que vão tentando desviar ele do ponto que deveria ficar. O aluno tem que ficar
mexendo essa válvula para tentar fazer, no papel de controlador, sempre que essa setinha
[que indica a temperatura] fique lá no zero. [...]. Primeiro, o aluno tem a percepção de como
o controle funciona, e segundo, para ele ver que tem algumas leis matemáticas que ficam por
traz que são intransponíveis. Ele pode achar "ah, esse controlador é mal feito”, mas se ele for
o controlador, se ele se colocar no papel de ficar mexendo na mão, tentando fazer essa
setinha ficar no zero, ele também não vai conseguir [...]. Existem restriçóes, existem
inviabilidades matemáticas que não permitem que o controle seja perfeito, ou seja, essa 
variável teria que ficar sempre naquele valor, mas dada a constituição do processo, o modo como ele se expressa matematicamente, não tem jeito, o processo vai ser desviado.

(Entrevista com E2, 2015)

No aspecto da docência, a Matemática tem sido trabalhada na forma de modelos matemáticos que envolvem, dentre outras coisas, equações diferenciais para abordar os processos de refino de petróleo e de controle desses processos. Para o trabalho de otimização em tempo real, por exemplo, ele utiliza diversos conceitos matemáticos. Entretanto, interessante ressaltar é a forma com que ele coloca a utilização da Matemática, ou seja, não se trata de discutir probabilidade, de encontrar pontos de máximo ou de mínimo de uma função, mas, sim, de responder a uma questão ou demanda de trabalho, como podemos ver a seguir:

tentar o tempo todo fazer a planta industrial caminhar para um ponto que ela dê mais dinheiro. Eu posso tomar mil decisões. Eu tenho mil válvulas, posso abrir e fechar mais ou menos cada uma delas. Qual a combinação boa para eu fazer isso de modo a conseguir o maior rendimento econômico para mim? Esse é o problema a ser resolvido [...]. Eu vou olhar para a planta, como ela está agora, e, baseado nessa informação que eu obtenho de todos os sensores que eu tenho lá, eu tento estimar o estado da planta. Será que os trocadores de calor estão sujos? Um monte de coisa que eu não consigo medir diretamente, mas que eu tento estimar indiretamente e, baseado nessas estimativas carregadas de um monte de premissas, eu tento compor [...] o modelo matemático mais atualizado do que acontece. Então, se esse aqui é o modelo, se essas são as equações, vamos otimizar, vamos mexer onde podemos mexer para ver se eu chego no final com mais dinheiro.

(Entrevista com E2, 2015, grifo nosso).

A engenheira E3, que atua em uma refinaria da Petrobras na área de Manutenção, fala que utiliza Matemática em algumas atividades de seu trabalho, como é o caso da análise de ocorrências, porém,

[...]focada num segmento específico que é a lógica, porque os equipamentos de automação são programados usando lógica: blocos lógicos, porta e, porta ou, flip-flop. A gente acaba tendo que usar, seja porque vai configurar um equipamento - que já não é bem uma atividade da Manutenção, é uma atividade de Engenharia, de implementar um projeto novo - ou porque eu tenho que analisar o comportamento desse equipamento, no qual eu tenho que entender o que foi configurado lá, aquela lógica que foi desenvolvida para compreender por que naquele momento aconteceu aquilo, naquele momento não aconteceu aquela outra coisa.

(Entrevista com E3, 2015).

E3 diz também que utiliza Matemática em suas atividades de tratamento de obsolescência, explicando esse uso do seguinte modo:

a nossa refinaria é uma refinaria antiga [...]. Então, você tem um equipamento que foi instalado há 30-40 anos, e a gente não tem mais peça de reposição ou, às vezes, a gente tem dificuldades de suporte do próprio fabricante [...]. O que temos que fazer? A gente tem que avaliar quais são os equipamentos que estão nessas condições e fazer um planejamento de substituição, ou seja, buscar uma solução que envolve o tipo de equipamento que eu posso colocar no lugar, se eu posso trocar o equipamento todo ou só uma parte, pois, às vezes, é só um componente que está obsoleto [...]. Então, esse é um tipo de trabalho que a gente se envolve muito. Nesse tipo de trabalho, deixa eu pensar se tem alguma matemática envolvida 
nessa análise. Vai ter na verdade... Orçamentação. Dá quase vergonha de chamar orçamentação de matemática, porque é somar e multiplicar, mas... eu diria que é isso.

(Entrevista com E3, 2015).

Ainda nos relatos de E3 vemos a Matemática aparecendo como lógica ou como orçamentação no contexto de algumas de suas atividades de manutenção da refinaria, como a análise de ocorrências e o tratamento de obsolescência, para que tudo funcione de forma correta e segura para não gerar perda de lucro para a empresa. Vemos, então, que tanto o engenheiro E2 quanto a engenheira E3 mencionam o aspecto do lucro, que se mostra fundamental no mundo empresarial.

O engenheiro E5, por sua vez, atua em outra refinaria e trabalha, basicamente, com o SDCD (Sistemas Digitais de Controle Distribuído) das unidades de processos da refinaria e da parte de automação de grandes máquinas. Para ele, a utilização da matemática em suas atividades está mais relacionada às operações básicas, de acordo com o trecho abaixo:

O conhecimento matemático... No dia a dia é complicado, não aparece muito, na eletrônica não aparece muito. [...]. Depende do nível de matemática que você está falando. [...]. Do ponto de vista de parar para calcular e resolver cálculos mais complexos, é muito difícil ter essa utilização. Às vezes, se utiliza de maneira básica na parte de controle, acertar um ganho, faz uma regrinha de três, uma coisinha um pouco mais complexa, do ponto de vista matemático. Cálculos e números, de utilização mesmo, não, quase nada. Essa coisa um pouco mais complexa seria usar uma] regra de três, somar mais alguma coisa e extrair uma raiz depois.

(Entrevista com E5, 2015).

No que diz respeito a E4, outro entrevistado que trabalha no Centro de Pesquisas e Desenvolvimento Leopoldo Américo Miguez de Mello (Cenpes) da Petrobras, argumentou que:

eu vejo a matemática como uma linguagem em que você extrai uma informação de uma realidade e consegue colocar ali, em termos de equações, de formulações do problema, para começar a entender o fenômeno.

(Entrevista com E4, 2015).

Ele afirma, ainda, que usa a Matemática para modelar os processos e os equipamentos através de, por exemplo, equações físico-químicas e correlações necessárias para o desenvolvimento de projetos de controle e automação de unidades da Petrobras. Em seus termos:

a gente usa matemática para modelar, para simular, para entender o que a gente quer. Com esse conhecimento, a gente desenvolve o projeto dos sistemas de controle e automação, coloca todas essas proteções e aí a gente usa também simulações para testar essa lógica configurada, muitas vezes, ainda em projeto, ou seja, a unidade nem partiu e a gente já faz essas simulações do que viria a acontecer. Depois que o projeto é feito, existe uma fase que você implementa nos computadores industriais, o que a gente chama aqui de SDCD, Sistemas Digitais de Controle Distribuído, que são os computadores adaptados ao meio industrial, com redundância e outras coisas. Há uma linguagem de programação desses equipamentos e você 
pega esse material que foi definido no projeto e tenta implementar ali. E a próxima fase seria fazer algoritmos de validação daquela lógica que está ali, porque muitas vezes você configura e acha que está perfeito, mas tem um erro, digamos assim, não percebido por quem configurou. Se você não tiver algoritmos que façam validação mais rigorosa, mais abrangente do que foi implementado, muitas vezes, você acaba percebendo o problema lá na operação, quando a fábrica já está operando. Só que, lá na frente, você tem um custo alto, com parada do equipamento. Então, esses algoritmos, esses softwares, tentam matematicamente explorar todas as combinações de eventos de forma que você possa identificar se acontecer um certo cenário como, por exemplo, a lógica que está configurada naquele sistema de automação vai travar ou vai se perder ou vai para uma situação que você não quer, etc. Quando a unidade começa a operar, aí existe toda uma série de algoritmos matemáticos que a gente usa para ajustar esses sistemas de controle, porque os simuladores ou emuladores do processo usados no projeto são imperfeitos e o processo real tem outra dinâmica, outras não linearidades que você não usou no seu modelo. O que a gente faz, normalmente, quando a unidade está operando é fazer alguns ensaios na saída desse controlador: a gente manipula algumas válvulas, a rotação do compressor, acelera, desacelera e, baseado nos dados obtidos nesses ensaios, você usa alguns algoritmos matemáticos para retirar modelos de como é o comportamento real daquela planta. Baseado nesses modelos, a gente usa outros algoritmos para ajustar os parâmetros dos sistemas de controle, que tem todo um embasamento matemático [...]. Finalmente, a gente fica olhando para o equipamento, para o processo, coletando pressões, temperaturas e vazões e usa esses dados com outros algoritmos para acompanhar indicadores, para calcular a eficiência desse sistema e poder acompanhar, ao longo do tempo, como essa eficiência está. Aí vem aquela parte que eu falei de usar alguns algoritmos para modelar essa degradação, como essa degradação está acontecendo, para poder prever uma manutenção, alguma coisa. Na área de automação essa é a visão geral, e em todas essas etapas têm vários algoritmos diferentes que a gente usa matemática, programas que, no fundo, são algoritmos que a gente implementou para aumentar a produtividade.

(Entrevista com E4, 2015).

Enfim, para ele, a Matemática é uma linguagem que

[...] ajuda a tentar ter "visões" para modelar o seu problema, olhar com ângulos diferentes e ver o que melhor te ajuda naquele problema específico. Ela permite modelar o processo, testar aquilo que foi projetado naqueles computadores para que não tenha erros, para que não gere problemas lá na frente, acompanhar essa operação, acompanhar a vida dos sistemas e voltar para melhorar o seu projeto.

(Entrevista com E4, 2015).

Ou seja, de acordo com E4, a Matemática é uma linguagem que contribui na modelagem e na resolução de problemas para que tudo o que ele e sua equipe projetam funcione de forma a atender as necessidades da empresa de forma segura, isto é, sem causar danos aos funcionários, aos equipamentos, enfim, à empresa como um todo.

As entrevistas com os engenheiros E2, E3, E4 e E5, como já destacamos, trazem relatos de atuações em diferentes áreas de negócio da Petrobras. Dentre eles, nos interessa aqui destacar que, embora todos sejam engenheiros que atuam com funções relacionadas à engenharia eletrônica, as formas com que se referem e descrevem as suas atividades indicam diferenças significativas entre os usos e os jogos de linguagem com que mobilizam os saberes matemáticos em suas práticas. 
Outros modos de falar de e sobre Matemática surgiram nas entrevistas realizadas com outros engenheiros eletrônicos da Petrobras, por exemplo, como disciplina (Cálculo), como conteúdos (multiplicação, derivada, integral, Transformada de Laplace), de forma adjetivada (matemática pura, matemática financeira, matemática simples, matemática aplicada, matemática pesada), aparecendo de forma implícita ou explícita.

Além disso, a Matemática também apareceu como ação: calcular uma torre de destilação de petróleo; usar as ferramentas ditas matemáticas para modelagem de processos e sintonia de controladores; ou como uma forma de entender os problemas, sendo acionada no próprio contexto de atividade.

Mesmo com diferenças significativas entre os usos e os jogos de linguagem com que mobilizam os saberes matemáticos em suas práticas, uma semelhança que notamos foi que a Matemática apareceu não como um fim, mas como um meio para falar de aspectos relacionados à prática profissional de engenheiros. Logo, ela é importante não em si mesma ou por seu aspecto operacional, mas por contribuir no desenvolvimento e na análise de diversas práticas profissionais dentro da Petrobras, práticas essas de caráter multidisciplinar, que visam performances profissionais cada vez melhores.

Desses modos de falar de Matemática, queremos destacar dois: 1) a Matemática como uma forma de entender problemas; e 2) a Matemática como auxiliar na tomada de decisões. A seguir, discutiremos esses modos concomitantemente ao que os engenheiros eletrônicos da Petrobras falaram sobre a Matemática nos cursos superiores de Engenharia, relacionando-a com suas práticas profissionais.

\section{A relação da Matemática em cursos superiores com a Matemática da prática profissional}

A Matemática, bem como os usos dela no mundo de trabalho - como relatada nas entrevistas -, difere do que é apresentado nos cursos de graduação. Novamente, tratam-se de diferentes jogos de linguagem sendo jogados, pois a universidade, em geral, se esforça para buscar maneiras que possam aproximar esses jogos, sendo uma delas as aplicações dos conteúdos teóricos estudados. Por exemplo, em um curso de Engenharia de Controle e Automação, essa aproximação dos saberes matemáticos ao mundo do trabalho pode envolver disciplinas em que os usos da Matemática se dediquem a aplicações dela ao campo eletrônico.

Porém, esse modelo universitário ainda se centra nas disciplinas e em seus conteúdos que são pensados de forma isolada. Nesse sentido, cabe ao professor da disciplina a 
responsabilidade de tentar construir tais conexões, o que é reforçado pelo modelo departamental das universidades, conforme discutem Cabral e Baldino (2004). Nesse mesmo sentido, E2 argumenta sobre o isolamento das disciplinas nas Universidades:

O problema na universidade é que as coisas são feitas de uma forma muito desconectada, são compartimentos estanques. Têm Cálculo I, II, III, IV, Álgebra Linear, etc. e aquilo são processos independentes, não estão unidos para mostrar a realidade como um todo e o aluno vai se acostumando com aquilo, vai vendo de forma independente. Muitas vezes, você vê que no final, quando [o aluno] vê um problema de verdade, ele não consegue juntar aquilo tudo. "Eu tenho todos esses conhecimentos, por que não junto tudo de uma vez?". Porque na cabeça dele aquilo não aparece de forma integrada, aparece como sendo aspectos de muitos probleminhas diferentes. Às vezes, eu vejo, ainda, as pessoas falando: "esse problema não, mas isso aqui não, isso é de processamento de sinais, não é de controle”, mas, na verdade, esses nomes são só facilidades que a gente dá [...] quando está em um ambiente de graduação. A matemática, o problema é uma coisa só. Aquela equação pode aparecer em todos os lugares possíveis e o aluno teria que ser capaz de ver isso. Eu vejo que na graduação, muitas vezes, não há um grande esforço de integrar o conhecimento.

(Entrevista com E2, 2015).

Ainda podemos observar essa proposição nos dizeres de E4:

durante a graduação os professores] não têm ideia de onde aquela pessoa vai trabalhar, então ela realmente tem Cálculo I, Cálculo II e por aí vai e, muitas vezes, o próprio professor não consegue fazer conexões com aplicações. Ele foca na linguagem matemática, nos teoremas, nos axiomas e para os alunos fica meio "seco", e vem a questão: "como é que vou aplicar?". Apesar que muitos livros de Cálculo têm exemplos, mas eles são teóricos. Vamos calcular a área, o volume, resolver uma equação diferencial que veio de um processo. Dependendo do curso, muitas vezes, os professores vão para os detalhes e o pessoal reclama. Realmente, existem vários cursos que dão essa base e, dependendo da sua direção, para onde você vai trabalhar, talvez não use tudo aquilo. Muitos que vão trabalhar na área financeira usarão um subconjunto de toda base que ele recebeu, no meu caso particular, eu realmente não trabalho com tudo o que eu vi na faculdade; uso um subconjunto, mas tudo aquilo ajuda. Você tem uma segurança maior de continuar aprendendo, buscar na matemática o que você precisa para resolver um certo problema. É o dilema da educação: não pode ser muito específico, porque são inúmeras as possibilidades de carreira hoje em dia, mas não pode ser superficial. A matemática ajuda porque ela dá uma base para você pegar um problema, escolher as equações a serem usadas, que tipo de modelagem você vai fazer e, aí, são inúmeras opções, desde as mais simples até as mais complexas.

(Entrevista com E4, 2015).

O entrevistado E5, ao comentar sobre as possíveis aproximações dos cursos de formação universitária com a prática profissional, destaca que a possibilidade de atuação de engenheiros é ampla e isso dificulta certas especificidades na formação, como da indústria petroleira.

No caso de E5, ele sentiu dificuldades no início, quando ingressou na Petrobras, e com o tempo foi aprendendo no próprio trabalho e na Universidade Petrobras como atuar, conforme vemos no seguinte trecho de entrevista:

eu sou formado em Engenharia de Computação [...]. Em 2010 teve concurso para REFAP [Refinaria Alberto Pasqulini] [...]. Me chamaram logo antes de reincorporarem a empresa ao sistema Petrobras [...]. Fiquei quase dois meses na manutenção, acompanhando os técnicos, 
indo para campo, vendo o que eles faziam. Eu, pelo menos, não conhecia nada de nada, não sabia nada de processo, não sabia nada de instrumentação; eu mal sabia o que era um CLP Controlador Lógico Programável - [...] um computador específico para aplicação industrial. Eu sabia só o conceito do que era, nunca tinha visto um CLP [...]. Foi meio difícil. Como eu não conhecia nada daquilo, ficava dificil saber no que eu tinha que prestar atenção, o que era importante, o que não era. Eu entrava no meio daquele monte de tudo, não conseguia reconhecer o que era o quê. Os instrumentos para mim eram todos iguais, porque todos eles por fora parecem iguais. Eles têm um invólucro para serem protegidos contra explosões [...]. Antes era "ah, a gente vai lá ver tal instrumento por causa disso e disso". Mas eu ficava me perguntando: "o que é esse instrumento?”, “qual é esse processo?”, "o que tem antes, o que tem depois?”, "por que a gente tem que ver isso?” [...]. Agora, eu tenho uma visão do todo, se tem alguma coisa que eu não entendo, eu sei o que perguntar ou onde procurar.

(Entrevista com E5, 2015).

Essa dificuldade em relacionar o que aprendemos ao contexto do mundo do trabalho é um tema bastante complexo. Vale destacar que o uso de conceitos matemáticos em diferentes contextos e situações diárias é difícil de ser abordado durante o percurso universitário, tanto pelo aspecto generalista da formação, como também por dificuldades dos professores. Estes últimos, mesmo tendo experiências diversas e familiaridade com o que denominamos por Matemática aplicada, não têm condições de abordar a variedade de aplicações possíveis nos distintos campos do mundo do trabalho. Assim, mesmo quando essa aproximação é feita, haverá situações não abordadas.

O problema que nos parece relevante a partir dos excertos aqui destacados são situações em que as disciplinas de Matemática não apontem para nenhuma aplicabilidade gerando dificuldades no campo de trabalho já que essa relação não é automática. Numa perspectiva wittgensteiniana, os usos e os sentidos da Matemática vão se construindo em seu contexto de uso. Por isso se faz importante estabelecer conexões com situações práticas, mesmo que limitadas.

Mas, para além das questões de ordem mais técnicas, há outros aspectos que merecem ser destacados sobre a prática profissional que nem sempre são trabalhados de forma explícita nas universidades, como a tomada de decisões e a forma de lidar com os problemas. Novamente o engenheiro E2 contribui para essa discussão:

[...] muitas vezes a universidade não olha muito para isso [preparar o aluno para tomar decisões], ela olha para aquela filosofia de você fazer as provas, de cumprir aquelas etapas, $e$ o aluno vai se condicionando a isso. Ele fica muitos anos no primeiro e segundo grau e depois muitos anos na faculdade sendo acostumado a ser medido pelos testes que vão fazendo. Ele vai aprendendo o que deve fazer para ter uma performance melhor [...]. [Isso] nem sempre garante uma boa atuação profissional, porque na atuação profissional o problema está em aberto, não tem um enunciado fechado, pronto, os dados não estão todos ali. Muitas vezes, os dados disponíveis são falsos, você vai ter que perceber que eles são falsos depois. Muitas vezes, o problema que te reportam não é o problema verdadeiro, você que vai ter que descobrir qual é o problema real mais tarde. Essa habilidade de observar as informações que estão acontecendo e aí propor diagnóstico para chegar à causa é o que falta para a 
engenharia e, muitas vezes, na universidade isso fica um pouco esquecido, ou, às vezes, porque a vivência do professor é uma vivência que não está diretamente conectada com esse uso final da engenharia ou, às vezes, por causa do hábito de que as coisas são assim. Tem um fator cultural muito forte na educação, [...] você vai repetindo a forma que você foi ensinado, depois vai ensinar assim de novo as outras pessoas. Então, as novidades, as formas diferentes de perceber acabam levando muito tempo até serem implementadas. Não que isso não aconteça aqui [na Universidade Petrobras], porque as pessoas são gente. Fazem provas e como gente são acostumadas aquelas coisas que já aprenderam, ao modo que foram ensinadas. Muitas vezes isso vai acontecer. O que a gente tem que ficar atento é pensar sempre: essa informação, esse conhecimento aqui tende a deixar ele mais apto para resolver os problemas da vida real ou será que a gente quer só fazer ele repetir o que as pessoas estão fazendo, preparo uma cartilha de instruções, faça isso, aquilo, aquilo outro, chega lá e ele fica repetindo isso? Na verdade, a gente tem que mostrar as lacunas que existem nos procedimentos, no modo como a gente opera para deixar o cara preparado para ele chegar lá e ser um gerador de coisas novas.

(Entrevista com E2, 2015).

Nesse recorte podemos ver, novamente, o papel do professor sendo colocado em questão. Por tradição ou por dificuldades com a prática profissional da Engenharia, os professores, incluindo os professores de Matemática, acabam não contribuindo para o desenvolvimento da capacidade dos alunos em tomar decisões e resolver problemas profissionais. Eles se focam em ensinar um conteúdo determinado e em propor exercícios de fixação que se tratam de uma aplicação direta do que foi abordado em sala de aula.

Sobre esse aspecto, o entrevistado E2 nos falou que, depois que começou a trabalhar, percebeu que tinha a informação ou o conhecimento necessário para sua prática profissional, mas que não estava preparado para organizá-los e propor boas soluções. Foi com o tempo de serviço que ele foi conseguindo trabalhar seus conhecimentos de forma mais integrada. Ademais, quando questionado se aprendeu alguma Matemática no trabalho, E2 respondeu que sim,

[...]mas são coisas que eu percebi. Acontece tal tipo de coisa, eu não consigo explicar isso com o meu conhecimento, então eu tenho que correr atrás, tentar formular isso de alguma forma [...] tentar uma forma de enxergar corretamente o problema. Muitas vezes, você não entende o problema porque não conseguiu formular ele bem para você mesmo, às vezes é uma coisa simples, mas você não consegue juntar as peças e dizer "ah, o problema é esse aqui, é isso, isso e isso aqui, como aconteceu aqui". Muitas vezes você está imerso no dia a dia e acha natural, intuitivo, coisas que não deveriam ser intuitivas.

(Entrevista com E2, 2015).

Essa fala nos levou a questionar se a pergunta estava clara ou não para E2, pois o objetivo era saber como ele falaria dessa Matemática que aprendeu no mundo de trabalho e a resposta foi:

quando você fala dessa matemática eu fico com dificuldade de entender o que você chama por matemática. Matemática é uma coisa tão vasta. [...] antes de dizer matemática, eu diria formas de entender o problema, como, às vezes, enxergar alguns problemas que parecem simples, que parecem intuitivos, mas colocar um formalismo matemático por trás, expressar 
ele do modo como ele deveria ser expresso. Isso que eu entendo como matemática que aprendi ao longo do tempo. Muitas vezes, essa capacidade de pegar o problema que tem uma roupagem que parece intuitiva, que o pessoal fala e tal, mas na verdade não é um problema bem posto, é um problema que não foi formulado com rigor, se vocêfizer isso você vai acabar tirando conclusões diferentes. Isso que eu acho que seria a resposta que eu poderia te dar. (Entrevista com E2, 2015).

Ainda que o significado da Matemática seja questionado pelo entrevistado, isso não o impediu de falar sobre ela e seu papel nas formas de entender problemas. Consideramos que, mais do que uma atividade de aplicação de conteúdos matemáticos, as situações mimetizadas do mundo de trabalho e o modo como a Matemática é vista nesse mundo nos trazem contribuições importantes para pensarmos a Matemática e seu aspecto disciplinar e disciplinador, como é o caso da relação da Matemática com a tomada de decisões a as maneiras de formular e de entender um problema.

As capacidades de tomar decisões e de ver (ou analisar) os problemas também são colocadas pela engenheira E3:

eu não acho que eu teria a capacidade que eu tenho hoje, como engenheira, de projetar, de analisar, de compreender os problemas, de propor soluções, se eu não tivesse passado por aquela etapa de formação básica [...]. Eu sei que muitas coisas que eu estudei na faculdade eu nunca usei e nem nunca vou usar, mas eu acho que ter estudado aquilo me deu a capacidade que eu tenho hoje, como a de análise, para aplicar aos problemas práticos que eu tenho que analisar, entender e discutir [...]. Por exemplo, quando você está avaliando a solução de um problema ou está tentando entender o problema em si, o que você precisa para fazer isso é uma capacidade de pegar aquele problema e de alguma forma desmembrar ele em partes, entender cada parte isoladamente, entender como as partes se juntam. Eu acho que essa capacidade de você entender um problema, dividir ele, entender as interações, é adquirida através do estudo da Física e da Matemática [...]. Agora, digamos que eu estou fazendo um projeto de um sistema novo. Eu não tenho um histórico passado. Eu sei o que eu quero que o sistema faça: é uma coisa meio de modelagem, conseguir transformar aquilo que você está vendo, ou o que você quer que aconteça, num equipamento, numa lógica. Eu acho que essa capacidade de abstração, essa capacidade de vincular os projetos no papel com os equipamentos no campo, é uma coisa meio... É sutil isso que eu estou falando, mas eu sou uma das pessoas que defende que essa capacidade vem dos problemas que a gente resolveu de Física e de Matemática durante a faculdade. Não é só Física e Matemática, claro! Eu tive Circuitos, eu fiz um monte de problema de circuitos. Eu fiz Controle, fiz um monte de problemas de controle.

(Entrevista com E3, 2015).

Nesse recorte, E3 nos traz um modo diferente de ver o papel da Matemática nos cursos superiores, que é o de contribuir com maneiras distintas de encarar os problemas profissionais. Assim, tanto a tomada de decisões como os modos de ver os problemas são aspectos que segundo E3 foram facilitados por sua formação básica de Matemática e Física o que, segundo ela, ajuda a desenvolver modos de analisar e de pensar do futuro engenheiro. A entrevista com E3 nos leva a pensar que sua experiência com a Matemática foi pautada por exercícios de pensamentos, ou seja, ela parece ter sido desafiada mais a pensar 
matematicamente do que a resolver questões mecanicamente. Isso nos permite discutir algumas perspectivas educacionais da Matemática em cursos de serviço que valorizem modos de pensar os conteúdos matemáticos mais do que técnicas de resolução.

\section{Uma perspectiva problematizadora e uma proposta de mudança de foco docente}

Nos cursos superiores, as disciplinas de Matemática (como Cálculo Diferencial e Integral e Geometria Analítica), possuem diversas possibilidades de abordagem. Existem casos em que essas disciplinas são trabalhadas sem qualquer compromisso com aplicações práticas, ou seja, se resumem a garantir uma exposição teórica dos conteúdos, seguida de exemplos e uma lista de exercício para aprimorar as técnicas de resolução.

Não estamos aqui dizendo que isso não é importante, mas os excertos das entrevistas que trouxemos para essa discussão nos apontam para o fato de que é preciso ir além. Nos parece claro a partir dos relatos, que o entendimento do conceito (que é muito mais que saber a técnica) não é suficiente para realizar aplicações. Ou seja, saber técnicas e conceitos não parece ser suficiente para aplicá-los em outras disciplinas da Engenharia ou em outros contextos de atividade.

Entretanto, conforme aponta Barbosa (2004), diversas formas alternativas de trabalhar disciplinas matemáticas no Ensino Superior vem sendo desenvolvidas. Essas experiências envolvendo, por exemplo, propostas centradas na modelagem matemática e no uso de tecnologias digitais da informação e da comunicação propiciam aos estudantes e professores pensar matematicamente, identificar e propor novos problemas, entre outras habilidades.

$\mathrm{O}$ que as entrevistas aqui apresentadas parecem destacar é a necessidade de ampliar essas experiências. Por isso, ressaltamos que o isolamento disciplinar também é um isolamento de prática profissional do professor de Matemática, que, nos parece, precisam analisar suas práticas de modo mais coletivo e compartilhado. Entendemos que se faz necessário pautar nisso com mais ênfase na formação matemática nos cursos superiores.

É preciso (re)considerar que as disciplinas são práticas que foram separadas por especificidades, como uma forma de contornar, controlar e organizar diferentes situações possíveis de serem enfrentadas no mundo profissional. Nessa tentativa de contorno, controle e organização, elas acabam contribuindo para um distanciamento entre os jogos de linguagem universitários e os jogos da prática profissional, pois deixaram de se atualizar.

Em todo caso, sempre haverá um distanciamento entre esses jogos de linguagem, já que seus contextos de atividade e objetivos de execução são diferentes, podendo apresentar 
algumas semelhanças de família. Na universidade, diferentes jogos de linguagem são jogados para formar pessoas, enquanto que, fora dela, outros são jogados para lidar com a prática profissional, entre outros contextos. Mas ainda que isso aconteça, o modo como apresentamos a Matemática, pela visão de alguns engenheiros eletrônicos da Petrobras, contribui para o modo como a vemos. A partir das entrevistas, pode-se ver a Matemática aparecendo de diversos modos, mas sempre voltada às questões profissionais.

Ademais, a resolução de problemas é algo com que os engenheiros se deparam o tempo todo, como é o caso da análise de ocorrências em uma refinaria ou da proposta de novas estratégias de controle de um processo. $\mathrm{O}$ ato de resolver problemas foi tido por alguns entrevistados como sinônimo do que é ser engenheiro, mas isso também pode ser visto como uma tendência na Educação Matemática (ONUCHIC, 1999; ONUCHIC; ALLEVATO, 2011).

Uma perspectiva de formação que tem sido levantada, no caso das engenharias, ainda que não fique restrita a elas, é o uso de práticas problematizadoras, como abordado por Aravena-Reyes (2014). Nessas práticas, há resolução de problemas, por ser algo legítimo nos campos de atuação profissional, assim como um deslocamento da ênfase na formação de engenheiros para a superação de dificuldades, como é o caso da inventividade técnica. Assim,

como forma de superação dessas dificuldades, explora-se a ideia da
"problematização", num contexto em que, para além de representar uma ação para
estabelecer um enunciado que revela uma ruptura com uma vida antecipada (um
obstáculo), ela exprime um complexo processo de invenção de novos modos de
existência (ARAVENA-REYES, 2014, p. 1).

Esse autor trabalha mais no sentido da problematização como possibilidade de invenção, inventividade técnica, considerando-a uma característica fundamental da engenharia que pode orientar o processo de formação de engenheiros, visando a autonomia dos estudantes por meio da articulação de saberes novos ou tradicionais, inventando problemas e trabalhando não somente com a realidade ou os problemas dados, mas com mundos possíveis.

Nessas práticas problematizadoras, as disciplinas são eliminadas, mas não excluímos, por exemplo, a Matemática universitária, porque ela desempenha um papel importante na Engenharia, chegando, muitas vezes, a ser vista como uma poderosa ferramenta para a resolução de problemas ou problematizações; e consideramos isso inquestionável. Eliminamos, aqui, um modo disciplinado que, muitas vezes, vê a Matemática pela Matemática, pouco contribuindo para as demandas profissionais.

Nesse processo de práticas problematizadoras, o professor de Matemática passa a ser um problematizador, mas ele não atua sozinho. Esse professor opera em conjunto com outros 
professores na invenção de um novo modo de se fazer a formação universitária. Ele passa a ser visto como um "rei sem reino", 9 engajado em um projeto de formação que tenta se aproximar de práticas profissionais.

Enquanto um projeto de práticas problematizadoras não é tomado como objeto institucional de formação universitária, um caminho pode ser iniciado, no nosso ponto de vista: a mudança da prática docente por meio do reconhecimento de diferentes modos de falar de e sobre matemática, assim como de utilizá-la no mundo profissional.

Exibir e comparar, por meio de entrevistas ou outros tipos de pesquisa, o que acontece na prática profissional e na prática de formação - na qual há uma ilusão de preparação talvez não seja nada mais, nada menos do que aprender a viver formas de vidas ${ }^{10}$ diferentes, que podem ser relacionadas e possuir semelhanças de família, mas isso não significa que elas tenham uma essência comum. Se há semelhanças, há, também, muitas diferenças. A forma contorna o caos, como dizia Lispector (2009), e não é viável colocar nos cursos universitários todo o universo de possíveis práticas do mundo de trabalho, mas é possível preparar os futuros profissionais para jogarem diferentes jogos de linguagem e agirem em determinadas situações, de forma a contribuir para suas futuras atuações.

Os conteúdos matemáticos fazem parte desse processo de preparação, mas o foco disciplinar pode ser colocado nas formas de agir. Por exemplo, se em determinado contexto de atividade, um aluno se depara com a análise de uma função do tipo $f(x)=1 /\left(1-x^{2}\right)$, com uma postura problematizadora, ele poderá tomar decisões de ações que possibilitarão um tipo de precisão para ela. Dessa forma, o aluno pode tentar de imediato traçar o gráfico da função estipulando valores aleatórios para as variáveis, gerando pontos no plano cartesiano e ligandoos em seguida, para ver o que acontece com esta função.

Ao fazer isso, pode ocorrer de o gráfico passar por onde ele nunca deveria passar, prejudicando a análise e contribuindo para a busca de outras estratégias, como inserir a função no software GeoGebra. O software gerará um gráfico que possibilitará analisar a função e levar o aluno a acreditar ou desconfiar que, a partir de alguns valores para x, a função será

\footnotetext{
${ }^{9}$ Essa expressão foi inspirada em Moita Lopes (2006).

${ }^{10} \mathrm{O}$ conceito de lebensform (formas de vida) aparece nas Investigações Filosóficas (WITTGENSTEIN, 2009), obra póstuma de Ludwig Wittgenstein. Ele está relacionado ao significado e uso de nossa linguagem, que requer três elementos: o primeiro diz respeito ao modo como as palavras são utilizadas (uso de regras); o segundo requer a observação do contexto em que se empregam palavras (jogos de linguagem); e o terceiro diz respeito às funções que elas (palavras) desempenham (formas de vida). A partir do conceito de formas de vida, a linguagem caracteriza-se pela sua ligação com as diversas práticas (linguísticas e não linguísticas) do agir humano. Exemplo, a palavra "tristeza" em si nada diz. Seu significado está dado somente pelas práticas sociais que governam o uso dessa expressão/palavra em uma forma de vida.
} 
sempre nula. Essa desconfiança pode, ainda, fazer com que o aluno mobilize conteúdos matemáticos de disciplinas como a de Cálculo Diferencial e Integral - encontrar primeiramente o domínio da função, depois fazer intersecção com os eixos coordenados, calcular limites para ver se existem assíntotas e, em seguida, calcular as derivadas de primeira ordem para encontrar os intervalos de crescimento da função e de segunda ordem para estudo de pontos de inflexão e concavidade da função - para poder analisar com outro tipo de precisão o comportamento da função em análise.

Nesse sentido, cabe ressaltar que, enquanto problematizador e não apenas resolvedor de problemas, essas formas de agir não se limitam a aspectos metodológicos, pois não se trata de formar o sujeito apenas com técnicas de análises e procedimentos de resolução de problemas. Não se trata de pensar somente sobre procedimentos traçados, mas, sim, de buscar outras possibilidades de se pensar o problema e também de propor novos problemas. Assim, não se trata somente de resolver, mas de inventar, de criar problemas.

Pelas falas da engenheira E3, o último modo de proceder se assemelha a uma de suas práticas. Se um equipamento falhou, ele não é simplesmente trocado, porque isso pode trazer alto custo. É feita uma análise para ver o que falhou, verificando se o problema foi com o equipamento todo ou apenas com algum componente dele. Nesse sentido, a engenheira afirma que passar pelo cálculo a ajudou na prática de um caso como esse, pois o que ela realiza hoje nesse processo de análise de ocorrências exige um jeito normativo de agir. Por isso, não se age de qualquer forma! Logo, não se trata de um problema em que devemos resolver a equação ou analisar o gráfico por si só, mas, sim, de analisar os dados e montar o problema atividade em que a matemática ajuda a traçar os critérios de entendimento e de ação.

Assim, considerando o saber como algo que se constitui em seu contexto de uso, sendo que seus sentidos são construídos conforme os diferentes jogos de linguagem a que pertencem e, ainda, que o modelo de formação universitária se mantém disciplinar, apostamos na necessidade de buscarmos outras possibilidades de se pensar a Matemática presente nos cursos de engenharia.

Pelos trechos das entrevistas que trouxemos para este artigo, vemos que não se age de maneira qualquer no mundo profissional, porque isso pode trazer consequências ruins para uma empresa e seus funcionários. Assim, a Matemática ajuda a traçar critérios de ação e ainda pode possibilitar o entendimento de uma situação, podendo ser um disparador para a proposição do problema e uma ferramenta tanto de sua criação, quanto de sua solução.

Esse modo de compreender a Matemática é algo que pode ser trazido de imediato para a formação de futuros profissionais, por isso, afirmamos que não se trata de resolver um 
problema matemático, mas de pensar matematicamente sobre situações e criar problemas, bem como critérios de ação.

\section{Referências}

ARAVENA-REYES, J. A. A problematização como invenção: fundamentos para a educação em engenharia. In: Revista de Ensino de Engenharia, v. 33, n. 2, p. 65-71, 2014.

BARBOSA, J. C. Modelagem matemática em cursos para não-matemáticos. In: CURY, H. N. (Org.). Disciplinas Matemáticas em cursos superiores: reflexões, relatos, propostas. Porto Alegre: Edipucrs, 2004. p. 63-84.

BAZZO, W. A.; PEREIRA, L. T. do V. Introdução à engenharia: conceitos, ferramentas e comportamentos. Florianópolis: Ed. da UFSC, 2006.

BRASIL, Conselho Nacional de Educação (CNE), Câmara de Educação Superior (CES). Diretrizes Curriculares Nacionais do Curso de Graduação em Engenharia. Brasília: CNE/CES, Resolução CNE/CES 11, de 11 de março de 2002.

CABRAL, T. C. B.; BALDINO, R. R. O ensino de matemática em um curso de engenharia de sistemas digitais. In: CURY, H. N. Disciplinas Matemáticas em cursos superiores: reflexões, relatos, propostas. Porto Alegre: Edipucrs, 2004. p. 139-186.

GEBAUER, G. O pensamento antropológico de Wittgenstein. Trad. Milton Camargo Mota. São Paulo: Edições Loyola, 2013.

JULIO, R. S. Contribuições wittgensteinianas para a realização e a leitura de entrevistas envolvendo matemática nas práticas de engenheiros. REVEMAT, Florianópolis (SC), v. 11, Ed. Filosofia da Educ. Matemática, 2016. p. 178-192.

JULIO, R. S. Jogos de linguagem [matemáticos] na profissão e na formação de engenheiros. 2015. 251 f. Tese (Doutorado em Educação) - Faculdade de Educação, Universidade Estadual de Campinas, Campinas, 2015.

LATOUR, B.; WOOLGAR, S. A Vida de Laboratório: a produção dos fatos científicos. Trad. Ângela Ramalho Vianna. Rio de Janeiro: Relume Dumará, 1997.

LISPECTOR, C. A paixão Segundo G.H. Rio de Janeiro: Rocco, 2009.

MIGUEL, A. Percursos Indisciplinares na Atividade de Pesquisa em História (da Educação Matemática): entre jogos discursivos como práticas e práticas como jogos discursivos. Bolema, Rio Claro (SP), v. 23, n. 35a, p. 1-57, 2010.

MIGUEL, A.; VILELA, D. S. Práticas Escolares de Mobilização de Cultura Matemática. Caderno Cedes, Campinas, v. 28, n. 74, p. 97-120, 2008.

MOITA LOPES, L. P. da. Introdução: uma linguística aplicada mestiça e ideológica: interrogando o campo como linguista aplicado. In: MOITA LOPES, L. P. da (Org.). Por uma linguística aplicada INdisciplinar. São Paulo: Parábola Editorial, 2006. p. 13-44.

NOSS, R.; HOYLES, C.; POZZI, S. Working Knowledge: Mathematics in Use. In: BESSOT, Annie e RIDGWAY, Jim (Org.). Education for Mathematics in the Workplace. Estados Unidos: Kluwer Academic Publishers, 2002. p. 17-35. 
ONUCHIC, L. de la R. Ensino-aprendizagem de Matemática através da resolução de problemas. In: BICUDO, M. A. V. (Org.). Pesquisa em Educação Matemática. São Paulo: Editora UNESP, 1999. p. 199-220.

ONUCHIC, L. de la R; ALLEVATO, N. S. G. Pesquisa em Resolução de Problemas: caminhos, avanços e novas perspectivas. Bolema, Rio Claro (SP), v. 25, n. 41, p. 73-98, dez. 2011.

SILVA, C. M. S. da. A Matemática Positivista e sua Difusão no Brasil. Vitória: EDUFES, 1999.

TELLES, P. C. da S. História da Engenharia no Brasil. Rio de Janeiro: Livros Técnicos e Científicos Editora S.A., 1984.

WITTGENSTEIN, L. Observaciones sobre los fundamentos de la matemática. Espanha: Alianza Editorial, 1978.

WITTGENSTEIN, L. Cultura e Valor. Lisboa: Edições 70, 1980.

WITTGENSTEIN, L. Investigações Filosóficas. Trad. Marcos G. Montagnoli. Revisão e apresentação Emmanuel Carneiro Leão. 6. ed. Petrópolis: Editora Vozes, 2009.

WITTGENSTEIN, L. Tractatus Logico-Philosophicus. Tradução, apresentação e introdução de Luiz Henrique Lopes dos Santos. 3. ed. 2 reimpr. São Paulo: Editora da Universidade de São Paulo, 2010.

Submetido em 16 de Abril de 2018. Aprovado em 06 de Novembro de 2018. 